\section{Correction: Are genital examinations necessary for STI screening for female sex workers? An audit of decriminalized and regulated sex workers in Melbourne, Australia}

The PLOS ONE Staff

The following information is missing from the Funding statement: EPFC is supported by an Australian National Health and Medical Research Council (NHMRC) Emerging Leadership Investigator Grant (GNT1172873). CKF and CSB are supported by an Australian NHMRC Leadership Investigator Grant (GNT1172900 and GNT1173361, respectively). The publisher apologizes for the error.

\section{Reference}

1. Turek EM, Fairley CK, Bradshaw CS, Chen MY, Vodstrcil LA, Snow A, et al. (2020) Are genital examinations necessary for STI screening for female sex workers? An audit of decriminalized and regulated sex workers in Melbourne, Australia. PLoS ONE 15(4): e0231547. https://doi.org/10.1371/journal. pone.0231547 PMID: 32298328

\section{f open ACCESS}

Citation: The PLOS ONE Staff (2020) Correction: Are genital examinations necessary for STI screening for female sex workers? An audit of decriminalized and regulated sex workers in Melbourne, Australia. PLoS ONE 15(5): e0232925. https://doi.org/10.1371/journal.pone.0232925

Published: May 4, 2020

Copyright: @ 2020 The PLOS ONE Staff. This is an open access article distributed under the terms of the Creative Commons Attribution License, which permits unrestricted use, distribution, and reproduction in any medium, provided the original author and source are credited. 